\title{
Genetic diversity analysis of wild Arracacia species according to morphological and molecular markers
}

\author{
Raúl Blas - Marc Ghislain - Maria del Rosario Herrera • \\ Jean-Pierre Baudoin
}

Received: 26 July 2006/ Accepted: 10 July 2007/Published online: 24 August 2007

(C) Springer Science+Business Media B.V. 2007

\begin{abstract}
A study of genetic diversity was conducted among four wild Arracacia species (A. elata, A. equatorialis, $A$. incisa and A. xanthorrhiza), using three accessions per species, 20 plants per accession referred to as a population, 100 morphological characters and five AFLP primer combinations producing 202 AFLP markers. Genetic diversity was well described using these morphological descriptors and AFLP markers. Analysis of molecular variance showed a total variation of $49.5 \%$ which was attributed to differences between species; variation between populations within species amounted for $25.8 \%$, while variation within populations accounted for $24.6 \%$. On the basis of morphological and molecular characteristics, accessions considered previously as A. equatorialis could be regrouped with A. xanthorrhiza. These comparisons and multivariate analysis resulted in the selection of 28 morphological characters considered as discriminant to identify the Arracacia species from Peru. According to our morphological and molecular analysis, three
\end{abstract}

R. Blas $(\bowtie)$

Facultad de Agronomia, Universidad Nacional Agraria, La Molina, Ap. 456, Lima 12, Peru

e-mail: rblas@lamolina.edu.pe

\section{Ghislain · M. del Rosario Herrera}

Centro Internacional de la Papa, Ap. 1558, Lima 12, Peru

\section{J.-P. Baudoin}

Faculté Universitaire des Sciences Agronomiques de Gembloux, Passage des Déportés, 2, Gembloux 5030, Belgique wild species of Arracacia genus were clearly identified: A. elata, A. incisa and A. xanthorrhiza. However, A. equatorialis which was not well identified botanically could be considered as very close to A. xanthorrhiza.

Keywords AFLP - Arracacia - characterization · descriptors $\cdot$ genetic diversity $\cdot$ taxonomy

\section{Introduction}

In the genus Arracacia Bancroft, the number of species growing from Mexico to Bolivia is not definitive according to the results reported by several authors: 24 species are recorded by Constance (1949), 28 species by Hiroe (1979), 55 species by Pimenov and Leonov (1993), and 30 species by Constance (1997). The "World Umbelliferae Database" in 2005 indicates 72 species (http://www.rbge.org.uk/data/ URC/Nomenclature). Most of these species names are provisional (Blas 2000). Arracacia genus has been studied mainly in Central and North America (Mexico) (Mathias and Constance 1944, 1968, 1973; Constance and Affolter 1995a, b). In South America, Knudsen (2003) mentioned 10 Arracacia species, distributed in the mountainous Andean region of Venezuela, Colombia, Ecuador, Peru and Bolivia. In this region, the last descriptions of new Arracacia species were reported in Venezuela (A. tilletti Constance and Affolter) and in Colombia (A. colombiana 
Constance and Affolter) by Constance and Affolter (1995a, b). In Peru, no taxonomical treatment of Arracacia specimens was developed for more than half a century, although six species were reported from this country: A. xanthorrhiza Bancroft, A. peruviana (Wolff) Const., A. andina Britt, A. equatorialis Const., A. incisa Wolff, and A. elata Wolff (Mathias and Constance 1962; Brako and Zarucchi 1993). Of these species, A. xanthorrhiza is the only cultivated arracacha of northern South America. However, at present, no reliable classification of the Arracacia genus from the Andean region is possible due to the poor representation of the above-mentioned species in different herbaria. This is the case for the four taxa: $A$. xanthorrhiza, A. peruviana, A. andina and A. equatorialis for which the botanical descriptions are incomplete and need further investigations.

This work is aimed at the study of Arracacia genus in Peru with two specific objectives in mind: to select useful characteristics for the identification of Andean species, and to estimate intraspecific and interspecific diversity. Prior to this study, we separated A. equatorialis from A. xanthorrhiza by analyzing original descriptions (Constance 1949; Mathias and Constance 1962) and looking at some representations from different herbaria. Distinction between the two taxa was based upon leaflets incision, shape and margin of involucel. On the other side, the species A. andina and $A$. peruviana could not be differentiated from $A$. xanthorrhiza due to the fact that they share similar morphological characteristics. The two species A. elata and $A$. incisa were clearly differentiated from the other four Peruvian Arracacia species (Blas 2005). A. elata was distinguished by its sprawling habit, spinuloseserrate leaflet margin, and absence of storage roots. $A$. incisa was identified by its smaller size and ovate to lanceolate, scarious and denticulate-margined involucel, which exceeds the flowers but is shorter than the fruit. On the basis of this preliminary study, four species from Peru were therefore considered in our analysis: $A$. elata, A. equatorialis, A. incisa and A. xanthorrhiza.

\section{Materials and methods}

Plant materials

Natural populations of the four wild species, A. elata, A. incisa, A. equatorialis and A. xanthorrhiza from eight Peruvian Departments, representative of wild arracacha in Peru, were collected and analyzed (Table 1). Dried herbarium were deposited at the "Herbario MOL" of the Universidad Nacional Agraria La Molina (UNALM) and true seeds, dried with silica gel, were deposited at the "Instituto de Biotecnologia" (IBT-UNALM). Seeds with silica gel were placed into sealed plastic bags and maintained at $-20^{\circ} \mathrm{C}$. For each species, three accessions and 20 plants per accession were sampled from three localities. The number of 20 plants per accession was determined according to a previous study on sample size estimation in Arracacia natural populations (Blas 2005). Taxonomic identification was checked according to the provisional artificial key for Arracacia species, proposed by Constance (1949) and to the comparison of our samples with herbarium material.

\section{Morphological data}

Morphological data of Arracacia species were taken on each area where the accessions were collected (Table 1). The observations on each plant covered 100 (54 qualitative and 46 quantitative) characters previously established by Blas (2005). These characters are indicated in Table 2 and cover the four distinctive morphological parts: the storage roots, the central rootstock, the aerial stems and the leaves (Fig. 1). The morphological descriptors and their states were established according to the provisional key of Arracacia species in South America proposed by Constance (1949), the descriptors proposed by Blas (1998), and additional field observations (Blas 2005). Characters of the aboveground parts were recorded at flowering time while those of the underground parts were recorded immediately after harvest. Color of some plant organs was described according to the color chart of the Royal Horticultural Society (1995).

\section{Data analysis}

For statistical analysis, data from 20 plants/accession and three accessions/species were used and considered as the Operational Taxonomic Unit (OTU). From data compiled according to the states of descriptors (Table 2), a matrix of 240 plants or OTUs $\times 100$ characters was constructed. 


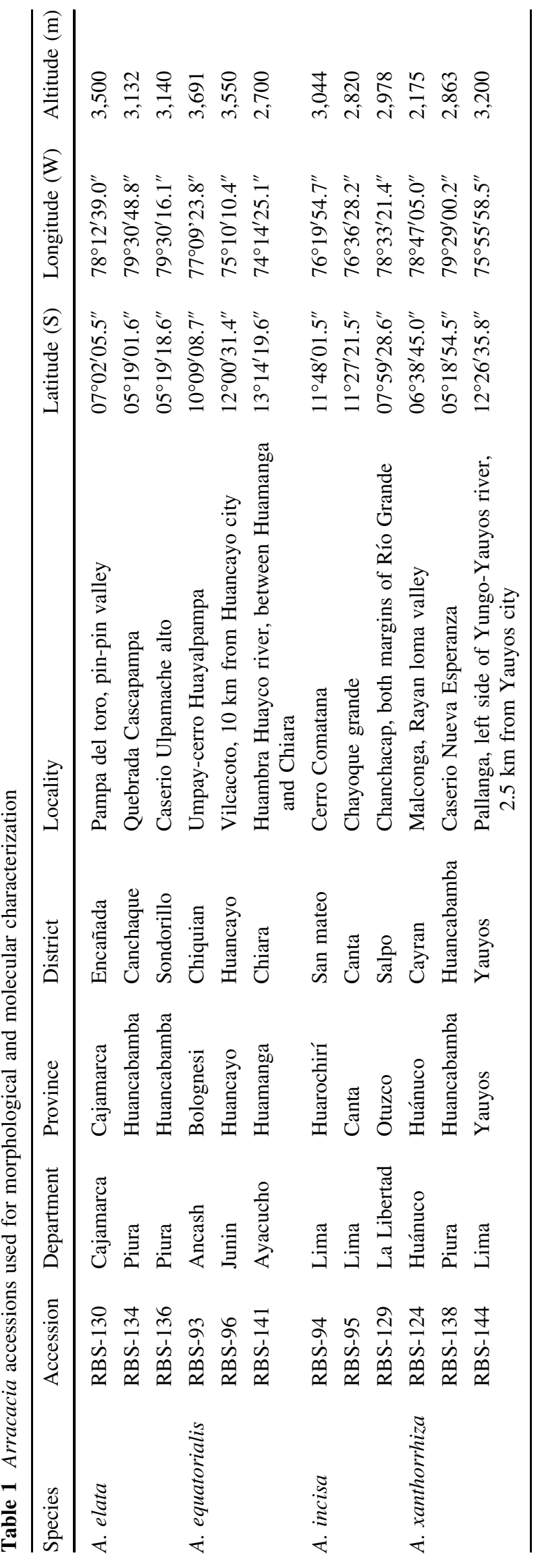

To evaluate the inter- and intra-species variances, descriptors for quantitative traits were analyzed using basic descriptive statistics and variance (ANOVA), with the help of Minitab 13.31 software (2000).

For multivariate analysis, each descriptor was standardized by subtracting the mean value from the observed value and dividing by standard deviation, in order to minimize the scale effects (Crisci and López 1983). Then, an exploratory analysis was elaborated with Principal Component Analysis (PCA) (Dagnelie 1986). A correlation symmetric matrix (100 variables $\times 100$ variables) was calculated in order to understand how the characters were associated and grouped. Eigenvalues and Eigenvectors were determined from this matrix, using the NTSYS 2.1 (Rohlf 2000) and Minitab 13.31 softwares. From these values, the accessions were plotted in order to identify population groups. Canonical Discriminant Analysis (CDA) was made using the procedure CANDISC of SAS system v8 (Palm 2000). The objective was to identify characters with high discrimination capacity for genetic diversity evaluation and to allow identification of Peruvian arracacha species.

\section{AFLP marker analysis}

DNA was extracted by the cetyltrimethylammonium bromide (CTAB) method of Doyle and Doyle (1990), adapted and standardized by CIP (1998). For DNA isolation, healthy young leaves were collected from natural populations and dried over silica gel.

The AFLP analysis was carried out according to Vos et al. (1995) and following manufacturer's instructions with minor modification (CIP 1998). Commercial AFLP kits were purchased from Invitrogen ${ }^{\mathrm{TM}}$ Life technologies (Carlsbad, California, USA). A sample of $450 \mathrm{ng}$ genomic DNA was digested in $12.5 \mu \mathrm{M}$ of $5 \times$ reaction buffer $[50 \mathrm{mM}$ Tris- $\mathrm{HCl}$ (pH 7.5), $50 \mathrm{mM} \mathrm{Mg-acetate,} 250 \mathrm{mM} \mathrm{K}$ acetate] with $1 \mu \mathrm{L} E c o R \mathrm{I} / \mathrm{Mse}$ I enzyme combination [1.25 units/ $\mu \mathrm{l}$ each in $10 \mathrm{mM}$ Tris- $\mathrm{HCl}$ (pH 7.4), $50 \mathrm{mM} \mathrm{NaCl}, 0.1 \mathrm{mM}$ EDTA, $1 \mathrm{mM}$ DTT, $0.1 \mathrm{mg} /$ $\mathrm{ml} \mathrm{BSA}, 50 \%$ glycerol (v/v), $0.1 \%$ Triton $\left.{ }^{\circledR} \mathrm{X}-100\right]$. Following digestion, $12.5 \mu \mathrm{l}$ of adapter/ligation solution containing $12 \mu \mathrm{l} \mathrm{EcoR} \mathrm{I/Mse} \mathrm{I} \mathrm{adapters,} 0.4 \mathrm{mM}$ ATP, $10 \mathrm{mM}$ Tris- $\mathrm{HCl}(\mathrm{pH} 7.5), 50 \mathrm{mM}$ K-acetate and $0.5 \mu \mathrm{T} 4$ DNA Ligase $(1 \mathrm{unit} / \mu \mathrm{l})$ was added directly to the DNA digest, incubated $2 \mathrm{~h}$ at $20^{\circ} \mathrm{C}$, 
Table 2 Morphological descriptors used in the diversity analysis of Arracacia wild species

Cormels and rootstock

1. Plant conformation: 1 climbing, 2 single, 3 lax, 4 medium, 5 compact (determined according to number of cormels and generative shoot development)

2. Life form: 1 monocarpic, 2 polycarpic [monocarpic plant is a plant that dies after flowering, although it may take several years to flower, and polycarpic plants are fruiting and flowering many times (De Candolle 1835)]

3. Cormels or branches presence: 0 absent, 1 present (1or 2 cormels), 2 ( $>2$ cormels) (determined in the field at sampling time)

4. Cormels number

5. Cormels surface color: 1 white, 2 yellowish-green, 3 yellow, 4 grayish-orange, 5 beige (brown clear), 6 brown, 7 purple red, 8 grayish purple

6. Cormels shape: 1 hole long tube, 2 conic, 3 ovoid, 4 oblong, 5 oblong long, 6 oblong divided

7. Cormels length $(\mathrm{cm})$

8. Cormels width $(\mathrm{cm})$

9. Rootstock shape: 1 hole long tube (root-stock absent), 2 conic 3 oblong-divided, 4 oblong long divided, 5 oblong with few cormels, 6 oblong with many cormels

10. Rootstock length $(\mathrm{cm})$

11. Rootstock width $(\mathrm{cm})$

Leaves

12. Leaves length $(\mathrm{cm})$

13. Leaves width $(\mathrm{cm})$

14. Pinnas' number of leaves

15. Leaves shape: 1 triangular-ovate, 2 ovate, 3 ovate-lanceolate (determined according to blade projection)

16. Foliage color : 1 clear green, 2 green, 3 dark green, 4 yellowish green, 5 yellowish purple green, 6 purple green, 7 dark purple green

17. Predominant petiole color: 1 clear green, 2 green, 3 yellowish green, 4 grayish orange, 5 grayish red, 6 purple red, 7 grayish purple

18. Secondary petiole color: 0 absent, 1 clear green, 2 green, 3 yellowish green, 4 grayish orange, 5 grayish red, 6 purple red, 7 dark grayish purple

19. Distribution secondary petiole color: 0 absent, 1 superior, 2 medium 3 inferior, 4 equally distributed, 5 irregular

20. Wax in petiole: 0 absent, 1 present (determined at the flowering time)

21. Petiole length $(\mathrm{cm})$

22. Petiole width $(\mathrm{cm})$

23. Sheathing shape of petiole: 1 cordate, 2 triangulate, 3 triangulate-long

24. Sheathing color of petiole: 1 white, 2 clear green, 3 yellow green, 4 rose, 5 red purple

Leaflet

25. Main leaflet adaxial color: 1 clear green, 2 green, 3 green-yellowish, 4 purple

26. Main leaflet abaxial color: 1 white, 2 clear green, 3 green, 4 green-yellowish, 5 purple

27. Secondary leaflet abaxial color: 0 absent, 1 green, 2 purple, 3 violet

28. Distribution of secondary leaflet abaxial color: 0 absent, 1 border, 2 veins, 3 rachis, 4 veins and rachis, 5 irregular

29. Leaflet margin color: 0 absent, 1 grayish orange, 2 purple red, 3 grayish purple, 4 dark purple

30. Acumen shape of leaflet: 1subacute, 2 acute, 3 largely acute

31. Leaflet adaxial surface (hairs presence): 1 glabra, 2 only in veins, 3 squamose

32. Leaflet shape: 1 triangular-ovate, 2 ovate-oblong, 3 ovate-lanceolate, 4 lanceolate

33. Terminal leaflet length $(\mathrm{cm})$

34. Terminal leaflet width $(\mathrm{cm})$

35. Leaflet division (incision of terminal leaflet or lobule): 1 superficial, 2 medium, 3 deeply incised

36. Leaflet margin: 1 mucronate-serrate, 2 serrate, 3 serrate-spinulose

37. Lateral leaflet length $(\mathrm{cm})$ 
Table 2 continued

38. Lateral leaflet width $(\mathrm{cm})$

39. Petiolule length at lower level of leaf, $(\mathrm{cm})$

40. Petiolule length at upper level of leaf, $(\mathrm{cm})$

Generative shoot and inflorescence

41. Flower: 0 absent, 1 rarely, 2 medium, 3 frequently

42. Generative shoot color: 1 clear green, 2 green, 3 yellowish green, 4 grayish orange, 5 grayish red, 6 purple red, 7 grayish purple

43. Wax in generative shoot: 0 absent, 1 present

44. Mature umbel color: 1 clear green, 2 green, 3 yellowish green, 4 green purple-red, 5 brown, 6 purple red, 7 violet

Bracteole

45. Involucel number

46. Involucel form: 1 entire conic, 2 oblong-linear, 3 ovate-acuminate, 4 ovate with wing sheathing, 5 oblong-lanceolate, 6 ovatelanceolate,

47. Involucel margin: 1 entire, 2 narrowly scarious-margined, 3 denticulate-margined

48. Involucel length (mm)

49. Involucel width ( $\mathrm{mm})$

50. Involucre number

51. Involucre form: 1 entire linear or lanceolate, 2 lanceolate with sheath, 3 lanceolate to ovate without sheath, 4 like leaflets

52. Involucre length ( $\mathrm{mm})$

53. Involucre broad $(\mathrm{mm})$

Umbel

54. Peduncle length $(\mathrm{cm})$

55. Peduncle width $(\mathrm{cm})$

56. Number of rays/umbels

57. Number of fertile rays/umbel

58. Ray length $(\mathrm{cm})$

59. Umbel form: 1 elongated flat, 2 flat, 3 conic flat

60. Umbelulle conformation (form): 1 elongated, 2 medium, 3 compact

61. Generative shoot (GS) length $(\mathrm{cm})$

62. GS width $(\mathrm{cm})$

63. Branches number of generative shoot

64. GS number/plant

Flower and fruit

65. Petal color: 1 greenish, 2 reddish brown, 3 dark-purple

66. Pollen grain color: 1 white, 2 rose, 3 red, 4 purple

67. Stylopodium shape: 1 pyramidal, 2 depressed

68. Number of umbels/GS

69. Number of flowers/umbellule

70. Number of hermaphrodite flowers/umbellule

71. Pedicel length $(\mathrm{mm})$.

72. Number of grains/GS

73. Number of grains/umbel

74. Number of grains/umbellule

75. Carpophore insertion: 1 bi-parted at $1 / 4,2$ bi-parted to base

76. Seed length $(\mathrm{mm})$

77. Seed width $(\mathrm{mm})$ 
Table 2 continued

78. Mericarp transection: 1 semi-rounded, 2 pentagon

79. Fruit shape: 1 rounded, 2 conic, 3 ovoid, 4 ovoid-oblong

80. Ribs: 1 acute, 2 very prominent, 3 very prominent and corky

81. Vittae number in the intervals

82. Vittae number on the commissure

83. Vittae breadth: 1 narrow, 2 medium, 3 broad (determined subjectively by comparison among samples in cross-section of seeds)

Storage Root

84. Root shape: 1 rootlet (not storage), 2 conic, 3 conic long, 4 fusiform, 5 oblong, 6 irregular

85. Number of roots per plant

86. Root length (cm)

87. Root width $(\mathrm{cm})$

88. Skin thickness: 1 very thin, 2 medium, 3 thick-detaches easily (determined subjectively by comparison among samples at sampling time)

89. Main root surface color: 1white, 2 yellow, 3 clear brown, 4 brown, 5 grayish

90. Secondary root surface color: 0 absent, 1 white, 2 yellow, 3 rose, 4 purple, 5 grayish, 6 black

91. Distribution of secondary root surface color: 0 absent, 1 at base, 2 medium, 3 apex, 4 entire root, 5 irregular

92. Shape of secondary root surface color: 0 absent, 1 stripes, 2 spots

93. Predominant storage root flesh color: 1 white, 2 yellow, 3 purple

94. Secondary storage root flesh color: 0 absent, 1 yellow, 2 rose, 3 purple

95. Distribution of secondary root flesh color: 0 absent, 1 in cambium, 2 pith (central region), 3 cortex, 4 irregular

96. Root oil: 1 very low, 2 medium, 3 abundant (determined subjectively by comparison among samples, 5 min after transection cut of storage root)

97. Root surface: 1 smooth (soft), 2 medium, 3 wrinkled (rough) (determined subjectively by comparison among samples at the sampling time)

98. Branch number of root: 1 rarely ( $0-1$ root division), 2 medium (2-3 root division), 3 dense ( $>3$ root division)

99. Root odor: 1 slight odor, 2 typical odor, 3 like anise (determined subjectively by comparison among samples 5 min after transection cut of storage root)

100. Root flavor: 1 sweet -slightly pungent, 2 medium pungency, 3 very pungent (the taste of storage root was determined subjectively by comparison among samples at the sampling time)

and subsequently diluted 10-fold in $1 \times \mathrm{TE}$ buffer (10 mM Tris- $\mathrm{HCl}$ (pH 8.0), $0.1 \mathrm{mM}$ EDTA).

Preamplification was performed in a total volume of $12.75 \mu \mathrm{l}$, containing $1.25 \mu \mathrm{l}$ of diluted digestion DNA template, $0.125 \mu \mathrm{M}$ of $E c o \mathrm{RI}+\mathrm{A}$ and $M s e \mathrm{I}+\mathrm{C}$ primers. PCR was performed in a MJ Research PTC-100 thermocycler (Global Medical Instrumentation Inc., Minnesota, USA) using the following temperature profile: 20 cycles of $30 \mathrm{~s}$ at $94^{\circ} \mathrm{C}, 30 \mathrm{~s}$ at $56^{\circ} \mathrm{C}$ and $60 \mathrm{~s}$ at $72^{\circ} \mathrm{C}$. The PCR products were diluted 10 times with water and used as templates for the selective amplification.

Five AFLP primer combinations were identified as best for selective amplification: E-ACT/M-CAC, EAAC/M-CTT, E-ACC/M-CTC, E-ACT/M-CTC and EACG/M-CTC. Selective amplification was carried out in a volumen of $10 \mu \mathrm{l}$ containing $3 \mu \mathrm{l}$ of diluted preselective PCR product, $0.05 \mu \mathrm{M}$ of EcoRI + ANN and $M s e \mathrm{I}+\mathrm{CNN}$ primers. PCR was performed with the following temperature profile: 12 cycles of $30 \mathrm{~s}$ at $94^{\circ} \mathrm{C}$, $30 \mathrm{~s}$ at $65^{\circ} \mathrm{C}$, decreasing $-0.7^{\circ} \mathrm{C} /$ cycle to $56,60 \mathrm{~s}$ at $72^{\circ} \mathrm{C}$; followed by 25 cycles of $30 \mathrm{~s}$ at $94^{\circ} \mathrm{C}, 30 \mathrm{~s}$ at $56^{\circ} \mathrm{C}$ and $60 \mathrm{~s}$ at $72^{\circ} \mathrm{C}$. Following amplification, $5 \mu \mathrm{l}$ of formamide loading buffer ( $98 \%$ formamide, $10 \mathrm{mM}$ EDTA, $0.1 \%$ each of xylene cyanol and bromophenol blue) was added, and the samples were denatured at $95^{\circ} \mathrm{C}$ for $5 \mathrm{~min}$. Amplified fragments were separated on $6 \%$ polyacrylamide denaturing gels with 29:1 Acrylamide/Bis solution. The gels were pre-run at $110 \mathrm{~W}$ for $20 \mathrm{~min}$ in $1 \times$ TBE (Tris base $1.8 \%$, Boric acid $0.6 \%$ and $0.5 \mathrm{M}$ EDTA $0.2 \%$ ), prior to the loading of $5 \mu \mathrm{l}$ of sample and, thereafter, run at $110 \mathrm{~W}$ for approximately $3.5 \mathrm{~h}$. Following electrophoresis, DNA was detected with silver staining (CIP 1998). 


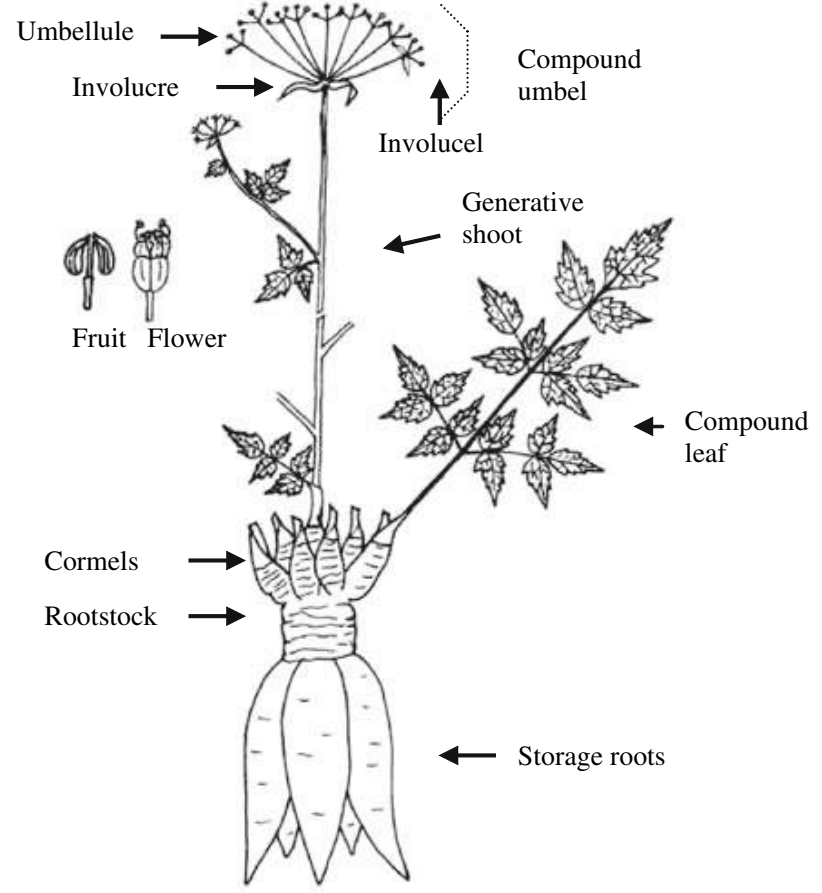

Fig. 1 Plant of cultivated Arracacia

Gel scoring and data analysis

Each polymorphic fragment produced by each AFLP primer combination was treated as a unit character and numbered sequentially on the APC film or directly analyzed using Paint Shop Pro 5.01 software (Jasc Corporate, MN, USA). Genotypes were scored for the presence (1) or absence (0) of each fragment, only those fragments with medium or high intensity were analyzed. Fragments with the same mobility on the gel, but with different intensities, were not distinguished from each other when OTUs were compared, so the AFLPs were treated as dominant markers. In order to characterize the capacity of each primer combination, and to reveal polymorphic loci in the germplasm, the polymorphic index content $(\mathrm{PIC})=1-\left(\mathrm{faa}^{2}+\mathrm{fan}^{2}\right)$ was calculated, where $\mathrm{faa}^{2}$ is the frequency of the amplified allele and $\operatorname{fan}^{2}$ is the frequency of the nonamplified allele. The highest value of PIC indicated the most informative AFLP marker. The PIC values for the AFLP markers generated by the same primer combination were cumulated and named AFLP marker index (Ghislain et al. 1997). This index indicates the information content of the AFLP primer by assay. We used Analysis of Molecular Variance (AMOVA) procedure (Excoffier et al. 1992) to estimate variance components at different levels, partitioning the variation among individuals/within population, among populations/within species and among species. This analysis was undertaken with Arlequin ver. 2000, a software for population genetics data analysis, provided by Laurent Excoffier (http://anthropologie. unige.ch/arlequin/; Department of Anthropology and Ecology, University of Geneva, Switzerland).

The genetic analysis was performed using the NTSYSpc 2.1 software (Rohlf 2000). Similarities between OTUs were calculated with the Simple Matching Coefficient $(\mathrm{SMC})=(a+d) /(a+b+c+$ $d$ ); where $a=(1,1)$ is the number of common fragments between two accessions, $d=(0,0)$ is the number of fragments absent in both accessions, $c=(0,1)$ and $b=(1,0)$ are the numbers of mismatches (Jaccard 1908, cited by Hancock 2004). According to this distance, the OTUs were plotted using nonmetric multidimensional scaling analysis (Rohlf 2000), in order to identify population groups.

\section{Results and discussion}

Morphological analysis

The univariate analysis of variance (ANOVA) for each of the 46 quantitative variables is detailed in Blas (2005). Data show highly significant differences $(P<0.001)$ between species for 43 characters, significant differences $(P<0.05)$ for one character [pinnas' number of leaves (14)] and no significant differences for two characters [involucre number (50) and vittae number on the commissure (82)]. The ANOVA between populations in each species show similar tendencies. Populations of A. xanthorrhiza show highly significant differences for 40 characters, no significant differences for five characters [rootstock length (10), rootstock width (11), involucel number (45), peduncle width (55) and number of hermaphrodite flowers/umbellule (70)]; one character [petiolule length at upper level of leaf (40)] does not show variation. Populations of $A$. equatorialis show highly significant differences for 26 characters, and no significant differences for 20 characters; all characters show variation in this taxon. Populations of A. incisa show highly significant differences for 18 characters, no significant differences for 27 characters; only one character does not show variation 
[petiolule length at upper level of leaf (40)]. Populations of A. elata show highly significant differences for eight characters, no significant differences for 28 characters, four characters [petiolule length at lower level of leaf (39), petiolule length at upper level of leaf (40), branches number of generative shoot (63), branch number of root (98)] do not show variation. The following six characters [cormels number (4), cormels length (7), cormels width (8), rootstock length (10), rootstock width (11), number of storage roots per plant (85)] are absent in the populations of A. elata.

With this analysis, we observe a high morphological diversity among the material analyzed at both between-species (A. elata, A. equatorialis, A. incisa and $A$. xanthorrhiza) and within-species (between populations or accessions) levels. This morphological diversity is higher in populations of $A$. xanthorrhiza, A. equatorialis and A. incisa than in populations of A. elata.

In general, in these species, a high variability is found for most of the morphological descriptors. However, this variability could have been inflated by environmental conditions as the data were recorded in different regions and ecosystems, at the time of our collecting missions.

\section{Principal Component Analysis (PCA)}

In the Principal Component Analysis, the first three principal components (PC) show respectively 35.3\%, $10.9 \%$ and $8.1 \%$ of the total variability. These low values mean that the populations and characters analyzed have high variability.

According to the first two PC, three groups of distribution are observed in plotting the 240 genotypes (Fig. 2). Group I represents the three populations of the species A. elata (accessions: RBS-130, RBS-134 and RBS-136); this group is positively related to the second component. A. elata is morphologically easy to identify by the absence of storage roots, rootstocks and cormels, by its plant size (more than $3 \mathrm{~m}$ ), its ovoid seed and its involucel shape and size.

Group II includes only a single population of the species A. xanthorrhiza (accession RBS-138); this population is isolated from the other A. xanthorrhiza populations; this group is positively related to the first component and negatively to the second component. This population is a wild form accession, morphologically very closely related to the cultivated ones and characterized by a high quantity of seeds and well-developed storage roots.

In Group III, eight populations are positively related to the first component, covering the three species: A. equatorialis (RBS-93, RBS-96 and RBS141), A. incisa (RBS-94, RBS-95 and RBS-129), and A. xanthorrhiza (RBS-124 and RBS-144). All genotypes of this group have storage roots, rootstocks and cormels. The RBS-95 and RBS-129 accessions of A. incisa are shown to be related to other populations corresponding to A. equatorialis, e.g. individuals corresponding to RBS-129 accession appear to be more related to accession RBS-141 of A. equatorialis. Concerning the three populations of A. equatorialis,
Fig. 2 Distribution of the 240 plants belonging to the four Arracacia species according to the first two PC

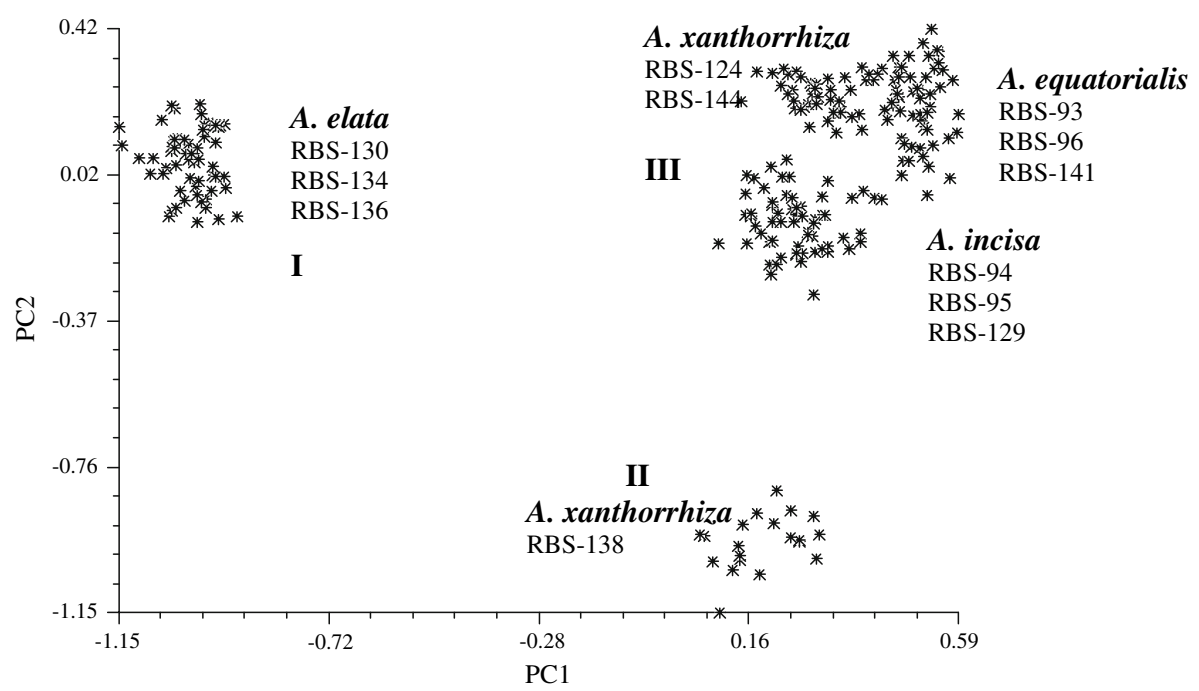


two accessions are grouped together, e.g. RBS-93 and RBS-141; the third population (accession RBS-96) is more related to A. xanthorrhiza populations.

The two populations corresponding to $A$. xanthorrhiza are grouped with the two different related species, i.e. A. incisa and A. equatorialis. For example, individuals corresponding to RBS-124 accession are clustered in different groups; some individuals being more related to A. equatorialis and others to A. incisa. However, inside Group III, differentiation between individuals is not easy, rendering necessary the definition of more discriminant characters. Such characters would be useful to better define groups and to obtain a reliable identification of the species. As a result, this analysis does not enable to differentiate clearly between populations corresponding to the three species A. equatorialis, A. incisa and A. xanthorrhiza.

\section{Canonical Discriminant Analysis (CDA)}

Three variables (of the 100 used) are eliminated due to a very low variability in the basic descriptive statistics and PC analyses previously made. These characters are: petiole length at upper level of the leaf (40), secondary storage root flesh color (94) and distribution of secondary storage root flesh color (95). In the CDA, the first three components explain all the variability (Table 3 ); the first component explains more than $92 \%$ of the total variation while the second component explains more than $5 \%$ of the total variation. Consequently, characters with great discriminant capacity for the genetic diversity analysis in arracacha are those that display high vector with the first and the second component of the canonical variables.

The criterion applied to identify discriminant characters is the absolute value of the Eigenvector coefficient (r) between the character and the canonical variable (Table 4). This coefficient should be $r \geq 0.5$. Considering this criterion, descriptors are reduced to fifty discriminant characters. Among the latter, the most important are in decreasing order the leaflet adaxial surface (31), stylopodium shape (67), number of rays per umbel (56), leaflet margin (36), storage root shape (84), rootstock width (11), vittae breadth (83), number of flowers per umbellule (69), cormel width (8), generative shoot length (61), plant conformation (1), petiolule length at lower level of leaf (39), cormels shape (6), and mericarp transection shape (78).

In the CDA, some characters used in the original descriptions to differentiate the Arracacia species do not have high discriminant values. This is the case for fruit length, fruit width, fruit shape, leaf length, and leaf width. On the other side, other characters in our analysis appear to have more discriminant power. These characters correspond to vegetative parts (cormels, rootstock and storage root) and generative parts (generative shoots, flowers and fruits). The characters corresponding to the underground vegetative parts were not taken into consideration in the original descriptions of the Andean Arracacia species, partly because most samples in the herbarium lack representations of these organs.

Considering the 50 selected descriptors, the 12 populations were analyzed in order to test the discriminant power of characters and to determine cluster of individuals.

These selected descriptors allow us to obtain a good clustering among the 240 plants of the 12 analyzed populations (Fig. 3). These populations are clearly separated into three groups: Group I includes three populations of A. elata, Group II includes three populations of $A$. incisa and Group III includes six populations corresponding to A. equatorialis and $A$. xanthorrhiza.

The three populations identified in A. equatorialis are not clearly separated from A. xanthorrhiza, indicating that the former taxon could not deserve the status of a species. Accordingly, populations of A. equatorialis could be classified together with populations of A. xanthorrhiza, because the
Table 3 Eigenvalue of the first three canonical variables and their proportion of variations

CAN $=$ Canonical variables, $P=$ probability

\begin{tabular}{lcclll}
\hline CAN & Eigenvalue & Difference & Proportion & Cumulative & $P$ \\
\hline 1 & 984.047 & 926.183 & 0.928 & 0.928 & 0.0001 \\
2 & 57.864 & 38.764 & 0.055 & 0.982 & 0.0001 \\
3 & 19.100 & & 0.018 & 1.000 & 0.0001 \\
\hline
\end{tabular}


Table 4 The 50 screened characters and the Eigenvector coefficient (r) between the character and the canonical variable

\begin{tabular}{|c|c|c|c|c|c|c|}
\hline CAN & $\mathrm{Ch}^{*}$ & $\mathrm{r}$ & $\mathrm{Ch}^{*}$ & $\mathrm{r}$ & Selected descriptors & \\
\hline \multirow[t]{24}{*}{1} & 31 & 0.933 & 71 & -0.719 & Cormels and rootstock & 49. Involucel width \\
\hline & 67 & 0.933 & 46 & -0.712 & 1. Plant conformation & 51. Involucre form \\
\hline & 56 & -0.904 & 65 & 0.707 & 3. Cormels presence & 54. Peduncle length \\
\hline & 36 & -0.894 & 60 & 0.696 & 4. Cormels number & 56. Number of rays/umbels \\
\hline & 84 & 0.890 & 37 & -0.693 & 6. Cormels shape & 57. Number of fertile rays \\
\hline & 11 & 0.879 & 48 & -0.686 & 7. Cormels length & 58. Ray length \\
\hline & 83 & -0.868 & 9 & 0.670 & 8. Cormels width & 59. Umbel form \\
\hline & 69 & -0.867 & 98 & -0.668 & 9. Rootstock shape & 60. Umbelulle conformation (form) \\
\hline & 8 & 0.864 & 66 & 0.628 & 10. Rootstock length & 61. Generative shoot (GS) length \\
\hline & 61 & -0.864 & 22 & -0.588 & 11. Rootstock width & 64. GS numbers/plant \\
\hline & 1 & 0.858 & 63 & 0.585 & & 65. Petal color \\
\hline & 39 & 0.844 & 49 & -0.578 & Leaves & 66. Pollen grain color \\
\hline & 6 & 0.826 & 3 & 0.578 & 15. Leaves shape & 67. Stylopodium shape \\
\hline & 78 & 0.814 & 32 & -0.563 & 22. Petiole width & 69. Number of flower/umbellule \\
\hline & 10 & 0.798 & 47 & -0.559 & 25. Main leaflet adaxial color & 71. Pedicel length \\
\hline & 99 & 0.796 & 38 & -0.553 & 26. Main leaflet abaxial color & 78. Mericarp transection \\
\hline & 58 & -0.787 & 91 & 0.530 & 30. Acumen shape of leaflet & 80. Ribs of fruit \\
\hline & 96 & 0.770 & 26 & 0.516 & 31. Leaflet adaxial surface & 81. Vittae number in the intervals \\
\hline & 59 & 0.767 & 30 & -0.513 & 32. Leaflet shape & 83. Vittae broad \\
\hline & 57 & -0.758 & 4 & 0.513 & 36. Leaflet margin & \\
\hline & 64 & -0.756 & 88 & 0.512 & 37. Lateral leaflet length & Storage Root \\
\hline & 7 & 0.750 & 15 & 0.507 & 38. Lateral leaflet width & 84. Root shape \\
\hline & 81 & 0.736 & 25 & -0.501 & 39. Petiolule length at lower & 86. Root length \\
\hline & 54 & -0.727 & 86 & -0.500 & & 88. Skin thickness \\
\hline 2 & 80 & 0.645 & & & Inflorescence and fruit & 91. Distribution of secondary root surface color \\
\hline \multirow[t]{3}{*}{3} & 51 & 0.570 & & & 46. Involucel form & 96. Root oil \\
\hline & & & & & 47. Involucel margin & 98. Branch number of root \\
\hline & & & & & 48. Involucel length & 99. Root odor \\
\hline
\end{tabular}

$\mathrm{Ch}^{*}=$ character number, following the arrangement of Table 2 (see Materials and methods), CAN = canonical variable

discriminant descriptors overlap between both taxa. This overlap in characters expression could be due to the natural gene flow between the two taxa and the production of viable hybrid seeds. To support this hypothesis, it is interesting to note that Knudsen (2003) obtained viable hybrid seeds in artificial crosses between cultivated and wild forms of A. xanthorrhiza in Cajamarca (Peru). Crosses could have occurred spontaneously between A. xanthorrhiza and A. equatorialis as the two taxa have the same geographical distribution. As A. xanthorrhiza was botanically described first, its status as species has to be preserved, should one decide to merge the two taxa in a single species. On the other part, populations of A. incisa and A. elata are clearly separated allowing easily their identification with the selected descriptors. The CDA shows that 48 characters out of the 50 present an eigenvector coefficient $r \geq 0.5$ with the first three canonical variables. The exception is for two characters: cormels number (4) and distribution of secondary root surface color (91). In spite of their high vector coefficients, we decided to discard the following characters: plant conformation (1), cormels length (7), cormels width (8), rootstock length (10), rootstock width (11), leaves shape (15), petiole width (22), main leaflet adaxial color (25), main leaflet abaxial color (26), lateral leaflet length (37), lateral leaflet width (38), petiolule length at lower level of leaf (39), involucel margin (47), involucre form (51), peduncle length (54), number of 
Fig. 3 Plotting of 240 plants with 50 selected descriptors according to the first two canonical variables $(1=$ A. xanthorrhiza, $2=$ A. elata, $3=A$. equatorialis, and $4=A$. incisa)

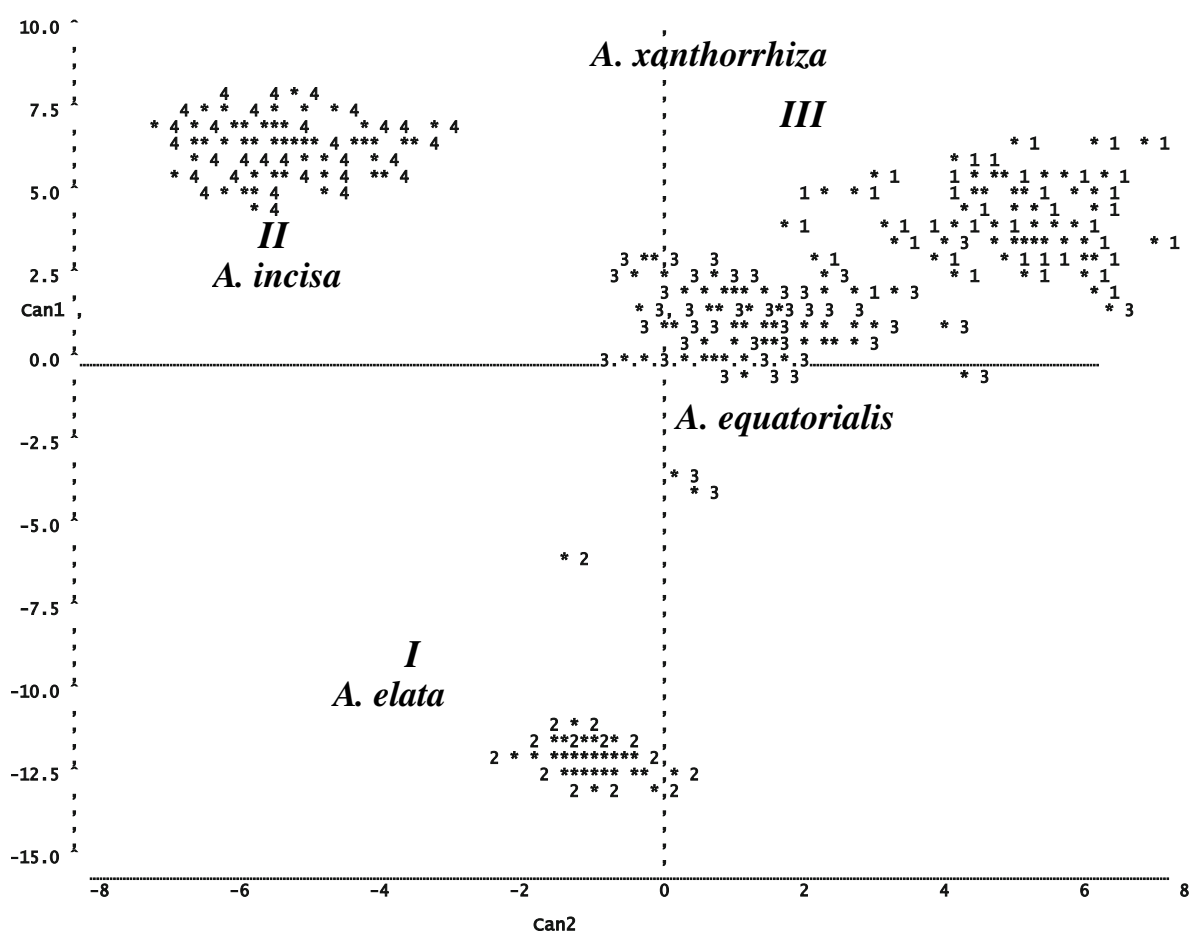

fertile rays (57), umbelulle conformation (60), pollen grain color (66), number of flower/umbellule (69), ribs of fruit (80), vittae number in the intervals (81), vittae breadth (83), root shape (84), root length (86), skin thickness (88), root oil (96), branch number of root (98), and root odor (99).

This is justified by the fact that we do not know the age of the evaluated material. As natural populations of arracacha are perennial plants, samples coming directly from natural areas do not represent a homogenized material. For instance, the length and the width of cormels, rootstocks and storage roots are "strongly" influenced by the environmental conditions, the soils where such material is found and the plant age. In addition, the color of the petioles and leaflets are not stable characters. However, these characters could be useful in some diversity analysis, such as at within population level.

On the basis of this consideration (CDA, Eigenvector coefficient), we selected 28 characters for identification of the Arracacia species from Andean region (Table 5). We also decided to include nine characters although they had in the CDA Eigenvector coefficient $r<0.5$ : life form (2), leaflet division (35), number of umbels/GS (68), number of grains/GS (72), carpophore insertion (75), seed length (76), seed width (77), fruit shape (79), and predominant storage root flesh color (93). We consider these characters as
Table 5 The 28 selected morphological descriptors for the identification of Arracacia wild species
Descriptors

Cormels and rootstock

2. Life form

3. Cormels presence

6. Cormels shape

9. Rootstock shape

Leaves

30. Acumen shape of leaflet

32. Leaflet shape

35. Leaflet division

36. Leaflet margin

Inflorescence and fruit

46. Involucel form

48. Involucel length

49. Involucel width
31. Leaflet adaxial surface
56. Number of rays/umbels

58. Ray length

59. Umbel form

61. Generative shoot (GS) length

64. GS numbers/plant

65. Petal color

67. Stylopodium shape

68. Number of umbels/GS

71. Pedicel length

72. Number of grains/GS

75. Carpophore insertion

76. Seed length

77. Seed width

78. Mericarp transection

79. Fruit shape

Storage Root

93. Predominant storage root flesh color very discriminant within each species due to their stability. Then, the discriminant capacity of these selected descriptors will be useful in further 
Arracacia species identification from the Andean region and the analysis of natural populations.

\section{Differences among Arracacia species of Peru}

Figure 4 illustrates the differences in vegetative and generative structures of these Peruvian species, considering stylopodium, carpophore, fruit, umbel, leaflet acumen, involucel, cormel and rootstock.

Arracacia elata is not likely to be confused with any of the Peruvian Arracacia species. In general, A. elata displays spinulose-serrate leaflet margin, ovoid fruit with acute apex, and ovate-lanceolate involucel.

A. incisa can be distinguished by the length of the involucel which exceeds the flower, the conspicuously scarious margins, and the semi-rounded seeds. In addition, $A$. incisa is characterized by a short plant size, combining short petioles and small and incised leaflets. Additionally, the taxon is geographically isolated, being present in hilly and dry areas of the Peruvian western and central highlands of Quechua region. A. incisa is closely related to A. xanthorrhiza through the shared compressed basal stem structures (cormels), the ramification of the flowering stem and the perennial growth habit.
A. xanthorrhiza includes cultivated form, as well as monocarpic and polycarpic wild forms. The A. xanthorrhiza cultivated form has many storage roots and well developed cormels, two properties distinguishing this form from other Arracacia specimens belonging to the group with the storage root. The A. xanthorrhiza monocarpic form differs from the A. xanthorrhiza polycarpic form and A. xanthorrhiza cultivated form by the monocarpic behavior (the root dying away after the end of flowering), the presence of one (or rarely 2) cormel and one (rarely 2) reproductive shoot per plant. In addition, this reproductive shoot is very vigorous and shows many ramifications that carry up to 1,000 seeds (Blas 2005).

A. xanthorrhiza polycarpic form differs from A. xanthorrhiza cultivated form, in having few and small cormels, and often a splitting fibrous root. A. xanthorrhiza polycarpic form is related to A. xanthorrhiza monocarpic form, but differ in some characters: the presence of cormels with several shoots, the few umbels or low amount of seeds/ generative shoot, the short plant size and the perennial behavior. Apparently, the A. xanthorrhiza polycarpic form appears to be the most closely related to A. xanthorrhiza cultivated form, sharing a perennial habit and similar ramifications of the flowering shoot, leaves, involucel and fruit shape.
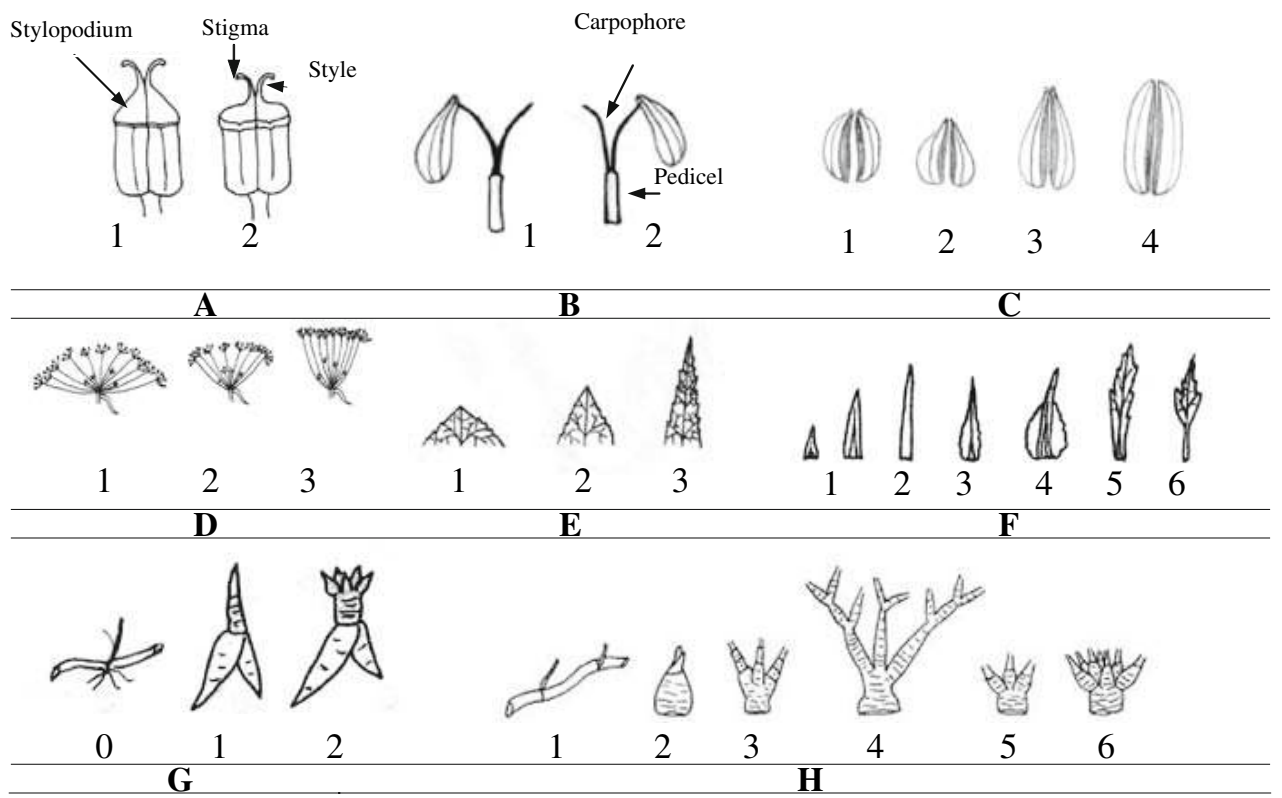

Fig. 4 Some morphological descriptors for the identification of Arracacia species: (A) Stylopodium shape; (B) Carpophore insertion; (C) Fruit shape; (D) Umbel form; (E) Acumen shape of leaflet; (F)involucel form; (G) Cormels presence and (H) Rootstock shape 
Molecular analysis

The five most informative screened primer combinations (E-ACT/M-CAC, E-AAC/M-CTT, E-ACC/MCTC, E-ACT/M-CTC and E-ACG/M-CTC) generate 202 AFLP reliable and reproducible markers. The highest values of AFLP marker index, showing the information content of the combinations of AFLP primers by assay, concern E-ACC/M-CTC, followed by E-ACT/M-CTC (Table 6). These two primers will be used in subsequent fingerprinting research in arracacha. Within species, very few unique polymorphic fragments are observed. A. elata shows three unique polymorphic fragments, representing only $1.5 \%$ of the total polymorphic fragments. No distinctive fragments are found for the species with storage roots, previously identified as A. incisa, A. equatorialis and A. xanthorrhiza (Table 6).

In general, the number of polymorphic bands is higher for A. elata than for the other species ( $A$. incisa, A. equatorialis and A. xanthorrhiza). A. elata presents $78.5 \%$ polymorphic bands of the total polymorphic fragments. A. incisa, A. equatorialis and $A$. xanthorrhiza show $37.6 \%, 44.1 \%$ and $47.6 \%$ polymorphic bands respectively. Polymorphism among populations within species presents the same tendency in the four analyzed species, varying from 36.5 to $60.2 \%, 24.8$ to $30.5 \%, 13.3$ to $28.7 \%$ and 23.2 to $26.7 \%$, respectively for $A$. elata, A. incisa, A. equatorialis and A. xanthorrhiza (Table 7).

The AMOVA analysis shows highly significant differences $(p=0.000$, determined from a 10,000 replication bootstrap) among the four species, among populations within species and within populations. The analysis shows that $49.5 \%$ of the total variation is attributed to differences between species, while variation among populations within species is
$25.8 \%$ of the total variation and the variation within populations accounts for $24.6 \%$ of the total variation (Table 8). This relatively high degree of genetic differentiation recorded between species, could be attributed to the geographic boundaries among species that do not facilitate gene flow among them. The high degree of variation within the populations could be explained by the widespread occurrence of wind pollination and breeding systems that promote outcrossing. Indeed, in arracacha, the presence of protogyny hinders self-fertilization and promotes outcrossing (Hermann 1997). Arracacha appears most likely to be a facultative outbreeder, giving progenies of genotypes with new genetic combinations. Another possible source for such pronounced genetic variation within populations might also result from hybridisations between wild and cultivated forms of A. xanthorrhiza or between A. xanthorrhiza and closely related species.

Three main groups are found after plotting the 12 populations with 202 AFLP markers according to nonmetric multidimensional scaling analysis (Fig. 5). The first group corresponds to the three populations of A. elata (RBS-130, RBS-134 and RBS-136). Individuals from each population are grouped closely, confirming previous results in the morphological analysis.

The second group corresponds to the three populations of A. incisa (RBS-94, RBS-95 and RBS-129); individuals from each population are grouped closely.

The third group includes six populations corresponding to the two species previously identified as A. xanthorrhiza (RBS-124, RBS-138, RBS-144) and A. equatorialis (RBS-93, RBS-96 and RBS-141). A population of $A$. equatorialis (RBS-96) is closely related to $A$. xanthorrhiza. The same tendency is reported from the morphological analysis.

Table 6 Primer combinations, marker index and polymorphic bands in each studied species

\begin{tabular}{lclllll}
\hline Primers & Polymorphic bands & Marker index & \multicolumn{4}{l}{ Unique fragments inside species } \\
\cline { 5 - 7 } & & & A. elata & A. incisa & A. equatorialis & A. xanthorrhiza \\
\hline E-ACC/M-CTC & 67 & 24.0 & 0 & 0 & 0 & 0 \\
E-ACT/M-CTC & 40 & 16.1 & 1 & 0 & 0 & 0 \\
E-AAC/M-CTG & 33 & 13.40 & 0 & 0 & 0 & 0 \\
E-ACT/M-CAC & 31 & 12.55 & 1 & 0 & 0 & 0 \\
E-AAC/M-CTT & 31 & 11.86 & 1 & 0 & 0 & 0 \\
Total & 202 & & 3 & 0 & 0 & 0 \\
\hline
\end{tabular}


Table 7 Polymorphic bands for each population and species

\begin{tabular}{|c|c|c|c|c|c|}
\hline \multirow[t]{2}{*}{ Species } & \multirow[t]{2}{*}{ Populations } & \multicolumn{2}{|l|}{ Per population } & \multicolumn{2}{|l|}{ Per species } \\
\hline & & Polymorphic loci & $\%$ poly $^{a}$ & Polymorphic loci & $\%$ poly \\
\hline \multirow[t]{3}{*}{ A. elata } & RBS-130 & 54 & 36.5 & 80 & 78.4 \\
\hline & RBS-134 & 73 & 56.6 & & \\
\hline & RBS-136 & 77 & 60.2 & & \\
\hline \multirow[t]{3}{*}{ A. incisa } & RBS-93 & 34 & 24.8 & 32 & 37.6 \\
\hline & RBS-96 & 36 & 28.6 & & \\
\hline & RBS-141 & 36 & 30.5 & & \\
\hline \multirow[t]{3}{*}{ A. equatorialis } & RBS-94 & 39 & 28.7 & 49 & 44.1 \\
\hline & RBS-95 & 19 & 13.5 & & \\
\hline & RBS-129 & 20 & 13.3 & & \\
\hline \multirow[t]{3}{*}{ A. xanthorrhiza } & RBS-124 & 36 & 26.7 & 50 & 47.6 \\
\hline & RBS-138 & 34 & 23.4 & & \\
\hline & RBS-144 & 32 & 23.2 & & \\
\hline
\end{tabular}

${ }^{\mathrm{a}}$ poly $=$ polymorphism

Table 8 AMOVA results for variation among species, among populations within species and within populations

\begin{tabular}{lrcccc}
\hline Source of variation & d.f.* & Sum of squares & Variance components & Percentage of variation & $P$ (value) \\
\hline Among species & 3 & 1251.008 & 5.87880 & 49.53 & 0.000 \\
Among populations within species & 8 & 514.200 & 3.06757 & 25.84 & 0.000 \\
Within populations & 228 & 666.600 & 2.92368 & 24.63 & 0.000 \\
Total & 239 & 2431.808 & 11.87005 & &
\end{tabular}

* d.f. = degree of freedom, $P=$ probability

Fig. 5 Plotting 240 plants of 4 Arracacia species according to nonmetric multidimensional scaling analysis with 202 AFLP markers

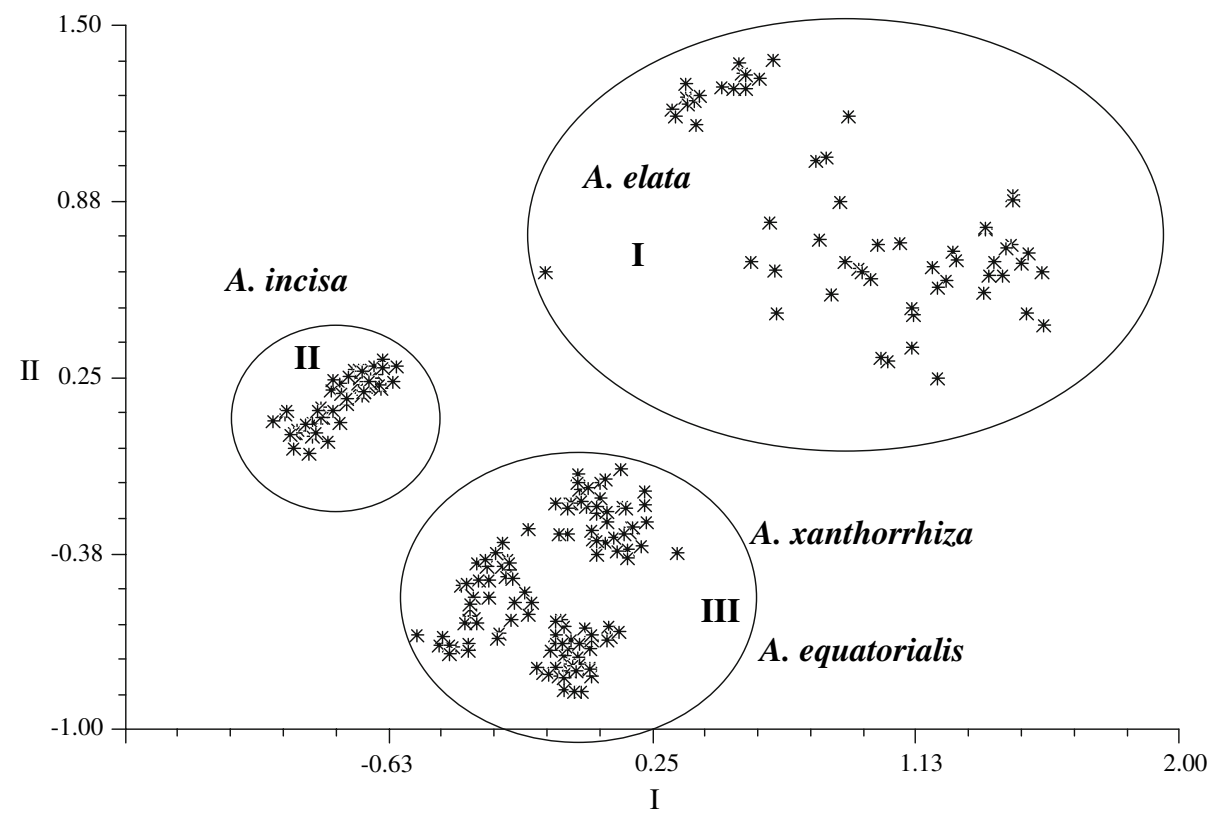


On the basis of morphological and molecular markers analysis, it is difficult to separate A. xanthorrhiza and A. equatorialis, indicating the closely related connection between them. Consequently, the identified taxon A. equatorialis could be considered as a different form within the A. xanthorrhiza species.

On the other side, A. incisa is a taxon deserving the status of species, in concordance with Constance's (1949) study; this conclusion is drawn from our morphological and molecular analysis. Therefore two species are recognized in the Andean region: A. incisa and A. xanthorrhiza; both of them have storage roots. One of them, A. xanthorrhiza, includes cultivated and wild forms; while the second, $A$. incisa, includes only wild forms. The A. xanthorrhiza cultivated form has many storage roots and well developed cormels, two properties distinguishing this form from other Arracacia specimens belonging to the group with the storage root (Blas 2005).

\section{Essential factors to clarify Arracacia taxonomy}

The clarification of the wild Andean Arracacia taxonomy is not an easy task due to the influence of various parameters, such as introgressive hybridisation between distinct species and hybrid speciation, phenotypic plasticity within species, morphological convergence among species and presence of the same ploidy level in the Andean Arracacia species (Blas et al. 1997; Blas 2005).

In particular, the extent and effect of hybridisation and introgression in wild Arracacia do not facilitate the botanical separation between some taxa and the phyletic understanding of the genus. The taxonomical differentiation among the wild Andean species is even more complicated when cross-compatible cultivated arracacha varieties occur in the vicinity of these wild populations: as those cultivated varieties are more variable phenotypically due to both anthropical and environmental influences, gene flow between the cultivated and wild forms hinders seriously the taxonomical identification of the Andean wild Arracacia. Hybridisation between Andean wild and cultivated arracacha genotypes have produced extensive hybrid swarms; some of them have been recognized as taxa while others are still considered as intermediate forms. This explains why some species associated to the Andean region like $A$. incisa and $A$. xanthorrhiza, show a complex pattern of variation with not well defined boundaries between genotypes of this group. This complex pattern might also result from the two following factors:

- Phenotypic plasticity which induces polymorphism in some morphological traits influenced by environmental components; this is illustrated by the high variation in leaf shape observed in several of the concerned taxa, depending on their ecological habitats;

- Weediness which is common in many representatives of this group displaying a preference for disturbed habitats (such as roadsides, boundaries of cultivated fields, or ancient ruins of the Peruvian civilization).

\section{Domestication process of Arracacia}

Andean South America seems to be the place of domestication of arracacha, although the genetic diversity of the genus Arracacia in other regions like Mexico is particularly high. According to Bukasov (1930), arracacha was domesticated in the southern region of Colombia where he found different varieties of arracacha. At present, in South America, the highest diversity of Arracacia wild species was found in Colombia and Venezuela. Nevertheless, these wild species are not closely related to $A$. xanthorrhiza, due to the lack of storage root. The wild species $A$. incisa and the wild forms of A. xanthorrhiza, bearing storage roots and cormels and resembling more closely the cultivated arracacha (A. xanthorrhiza), present high genetic diversity in the Andean region, from where they probably originated. Arracacia xanthorrhiza is widely distributed through Bolivia, Peru and Ecuador from 2,000 to $4,000 \mathrm{~m}$; whereas $A$. incisa is confined to the highland areas between the central and southern regions of Peru (Blas et al. 2007). A. incisa is the species more closely related to A. xanthorrhiza (Blas 2005).

So far it is not possible to elucidate clearly the origin of cultivated arracacha. Chromosome or gene mutations, selection in the wild forms, as well as hybridization between wild forms or between 
A. incisa and A. xanthorrhiza are all hypothetical ways to explain the origin of the cultivated arracacha. One of the farmers we met during our field survey in the region of Cajamarca considered that a selection of wild forms during three consecutive cycle at small farm level could lead to the development of domesticated form.

Evidences of Andean domestication are indicated by the uses of wild arracacha in medicinal or religious activities and as plants providing animal and human food since pre-Inca's time (Blas 2005). There are some historical references about preColumbian cultivation of arracacha in Ecuador, Colombia and Peru, which were documented by Spaniard chroniclers during the conquest of South America (Cobo 1956). In addition, there is some archeological evidence, such as Nazca pottery designs more or less 2,000 years old (Yacovleff and Herrera 1934). This pre-Inca culture developed in the Central and South Peru, covering coastal and highland parts. Only, in this region, the species A. incisa considered as the most closely related to $A$. xanthorrhiza is found. The precise site of arracacha origin is difficult to establish in this context, but undoubtedly arracacha was domesticated in the Andean region, perhaps in the Southern region of Peru. This area corresponds to Ayacucho, Apurimac, Huancavelica, Cuzco Departments, the cradle of ancient cultures of the Inca Empire like Nazca and Chancas.

\section{Conclusions}

The 28 most discriminant morphological characters were selected to identify Arracacia species. These descriptors contributed to the distinction between the three species known from Peru: A. elata, A. incisa and $A$. xanthorrhiza. Each species was also well differentiated along its evolutionary process. For example, A. elata grows in eastern humid highlands, while A. incisa is geographically confined to the hilly and dry area of Peruvian central and western highlands (no rain for 7 months). The species A. equatorialis and A. xanthorrhiza share the same ecological and geographical distribution throughout all Peruvian Inter-Andean valleys (no rain for 5 months), which favors constant gene flow between them (Blas 2005) and even the likely production of viable hybrid seeds. Differentiation between these two taxa is not easy due to overlapping of morphological characters. The high morphological diversity among the species (A. elata, A. equatorialis, A. incisa and $A$. xanthorrhiza) and between the different populations analyzed in each of them could also be the result of environmental conditions, as samples were collected and evaluated in different regions. Molecular characterization (with 202 AFLP markers) in this material also showed a high diversity among species and inside populations. The magnitude of genetic differentiation between and within species suggests that the population size must be large enough to maintain such levels of genetic variation over time. The genetic analyses presented here could be used to develop conservation strategies for the species, for example through the definition of appropriate units for plant genetic resources management. In order to help explain the role of such units of conservation, the nature of (seed, pollen) dispersal mechanism, the pattern of gene flow within and between populations or species and their effects on reproductive and demographic processes should be further investigated. Patterns of variation in quantitative genetic traits should also be clarified in the building of conservation plans.

Morphological and molecular marker analysis do not separate obviously A. xanthorrhiza and A. equatorialis, indicating the close relation between them. For this reason, the populations corresponding to A. equatorialis could be considered as populations of $A$. xanthorrhiza and therefore the taxon might not deserve the status of a species. Consequently, our morphological and molecular analysis identified clearly at this stage three wild species of Arracacia genus: A. elata, A. incisa and A. xanthorrhiza. However, to clarify taxonomical differentiation, particularly between $A$. xanthorrhiza and A. equatorialis, it will be useful to validate the most discriminant characters among the studied populations, by comparing their performance and stability in multilocation trials.

Analysis of the wild arracacha genetic diversity for agronomical traits such as resistance to drought and decay of storage roots is also important to improve the cultivated arracacha. Incorporation of these desirable characteristics into existing cultivars will 
be useful to overcome the limiting agricultural factors of this Andean neglected crop.

Acknowledgements This research was supported by grants from Coopération Universitaire au Développement (CUD) and Direction Générale de la Cooperation Internationale, Belgium.

\section{References}

Blas R, Arbizu C, Rodriguez G (1997) Número de cromosomas de la arracacha (Arracacia xanthorrhiza Bancroft). Anales Cientificos 32:44-54

Blas R (1998) Caracterización y evaluación de arracachas cultivadas (Arracacia xanthorrhiza Bancroft) del Perú. Tesis M. Sc., Universidad Nacional Agraria La Molina. Lima, Perú, $100 \mathrm{pp}$

Blas R (2000) Diversité génétique et éléments de physiologie chez l'arracacha (Arracacia xanthorrhiza Bancroft). Mémoire de fin d'études du Diplôme d'Etudes Approfondies, Faculté Universitaire des Sciences Agronomiques de Gembloux, Belgique, $67 \mathrm{pp}$

Blas R (2005) Diversity of Arracacia species in Peru. Ph.D. thesis. Gembloux Agricultural University, Belgium. $154 \mathrm{pp}$

Blas R, Hermann M and Baudoin J-P (2007) Analysis of the geographic distribution and relationships among Peruvian Arracacia wild specie. Genet Resour Crop Evol (in press)

Brako L, Zarucchi J (1993) Catálogo de las angiospermas y gimnospermas del Perú. Vol. 45, Missouri Botanical Garden, St. Louis, Missouri, USA, 1286 pp

Bukasov SM (1930) Las plantas cultivadas de Mexico, Guatemala y Colombia. Leningrado, Rusia. Traducido de la versión inglesa de M.H. Byleved por Jorge León (1985). CATIE Unidad de Recursos Genéticos, Turrialba, Costa Rica, $168 \mathrm{pp}$

Centro Internacional de la Papa (CIP) (1998) Molecular biology laboratory protocols: plant genotyping. Herrera MR, Zhang D, Ghislain M (eds) Genetic Resources Department, training manual, CIP, 2nd edn, Lima, Peru, 40 pp

Cobo PB (1956) Biblioteca de autores españoles, desde la formación del lenguaje hasta nuestros dias. Tomo I, Libro IV Estades, Artes Graficas. Madrid, España, pp 154-199

Constance L (1949) The South American species of Arracacia (Umbelliferae) and some related genera. Bull Tor Bot Club 76(1):39-52

Constance L (1997) An instance of East-West confusion in Chinese Umbelliferae, or Arracacia out of Asia. Edinb J Bot 54(1):99-104

Constance L, Affolter JM 1995a. Arracacia ravenii (Apiaceae), a new species from southern Mexico. Novon 5:22-23

Constance L, Affolter JM 1995b. Three new species and a new combination in Arracacia Bancroft (UmbelliferaelApiaceae). Brittonia 47(3):320-327

Crisci J, López M (1983) Introducción a la teoría y práctica de la taxonomía numérica. Serie de biología No.26, Secretaria General de la Organización de los Estados Americanos (OEA). Programa Regional de Desarrollo Científico y Tecnológico, Washington D.C., 132 pp
Dagnelie P (1986) Analyse statistique à plusieurs variables. $3^{\text {eme }}$ réimpression, Les Presses Agronomiques de Gembloux, Gembloux, Belgique, 362 pp

De Candolle A (1835) Introduction à l'étude de la Botanique, traité élémentaire de cette science. Tome I, Librairie Encyclopédique de Roret, Paris, France, 534 pp

Doyle JJ, Doyle JL (1990) Isolation of plant DNA from fresh tissue. Focus 12:13-15

Excoffier L, Smouse P, Quattro J (1992) Analysis of molecular variance inferred for metric distances among DNA haplotypes: application to human mitochondrial DNA restriction data. Genetics 131:479-491

Ghislain M, Zhang D, Fajardo D, Huamán Z, Hijmans R (1997) Genetic diversity analysis in a cultivated Andean potato, S. phureja Juz. et Buk. The International Potato Center (CIP), Program Report 1995-1996. Lima, Peru, pp 77-83

Hancock JF (2004) Plant evolution and the origin of crop species, 2nd edn. CABI Publishing, Wallingford, UK, $313 \mathrm{pp}$

Hermann M (1997) Arracacha (Arracacia xanthorrhiza Bancroft). In: Andean roots, tubers: Ahipa, arracacha, maca and yacon. Promoting the conservation and use of underutilized and neglected crops. In: Hermann $M$ and Heller J (eds) Institute of Plant Genetics and Crop Plant Research, Gatersleben/International Plant Genetic Resources Institute, Rome, Italy, pp 75-172

Hiroe M (1979) Umbelliferae of the World. Ariake Book Company, Tokyo, Japan, $2129 \mathrm{pp}$

Jaccard P (1908) Nouvelles recherches sur la distribution florale. Bull Soc Vaudoise Sci Nat 44:223-270

Knudsen SR (2003) Reproduction biology of the Andean root crop arracacha (Arracacia xanthorrhiza Bancroft var. xanthorrhiza) and the taxonomic status of the South American Arracacia Bancroft species with special emphasis on the position of the cultivated arracacha and related wild species. Ph.D. thesis. Botanical Section, Department of Ecology, The Royal Veterinary and Agricultural University. Copenhagen, Denmark, $150 \mathrm{pp}$

Mathias ME and Constance L (1944) Arracacia. North American Flora. The New York Botanical Garden. 28B (Part 1): 90-102

Mathias ME and Constance L (1962) Arracacia Bancroft. In: Mathias ME and Constance L (eds) Flora of Perú. Field Mus Nat Hist Bot 13(1) Part V-A: 13-19

Mathias ME, Constance L (1968) Two new apioid Umbelliferae from southern Mexico. Collectanea Botanica 7(Fasc. II, no. 43):759-766

Mathias ME, Constance L (1973) New and reconsidered Mexican Umbelliferae. Contr Univ Michigan Herbar 11(1):1-24

Palm R (2000) L'analyse de la variance multivariée et l'analyse canonique discriminante: principes et applications. Notes de statistique et d'informatique 2000/1, Faculté Universitaire des Sciences Agronomiques, Gembloux, Belgique, $40 \mathrm{pp}$

Pimenov MG, Leonov MV (1993) The genera of the Umbelliferae . Royal Botanic Gardens, Kew, UK, 156 pp

Rohlf F (2000) NTSYS PC: Numerical taxonomy and multivariate analysis for the IBM PC microcomputers (and 
compatibles), version 2.1 user guide. Applied Biostatistics Inc. Stony Brook, New York, USA, 39 pp

Royal Horticultural Society (RHS). (1995) Colour Chart. London, UK

Vos P, Hogers R, Bleeker M, Reijans M, Van de Lee T, Hornes M, Frijters A, Pot J, Peleman J, Kuiper M, Zabeau M
(1995) AFLP: a new technique for DNA fingerprinting. Nucleic Acids Res 23(21):4407-4414

Yacovleff E, Herrera F (1934) Racacha. En: El mundo vegetal de los antiguos peruanos. Botánica Etnológica. Revista del museo nacional, Lima, Perú 3(3):309-310 